\title{
Choice and frequency measures of stimulus control following simultaneous discrimination
}

\author{
K. G. WHITE \\ University of Otago, Dunedin, New Zealand
}

Four pigeons were trained to discriminate between simultaneously presented line-tilt stimuli in a discrete-trial procedure. Generalization tests using the method of paired comparisons were administered at different stages during discrimination training. Stimulus control functions derived from the choice measures thus obtained closely corresponded to functions derived from response frequencies to the test stimuli during the 10th test.

Measurement of stimulus control established during successive discrimination has typically utilized the free-responding procedure developed by Guttman \& Kalish (1956). Honig (1962) used this method to obtain generalization gradients following simultaneous wavelength discrimination. The gradient obtained when responses to each of a pair of simultaneously presented test stimuli were summed over all stimulus values was peaked at the stimulus value $(\mathrm{S}+)$ originally reinforced during training. Furthermore, responding to the previously nonreinforced stimulus (S-) was lower than to the stimuli adjacent to $\mathrm{S}-$.

Jenkins (1965) has advocated the use of discrete-trial procedures in the measurement of stimulus control. If the organism's response terminates each trial during training and testing, then the consequence of the response cannot be used as a basis for subsequent responding. For example, Nevin (1967) found that in a discrete-trial simultaneous brightness discrimination, the probability of a correct response remained constant despite variations in the overall probability of reinforcement. The present experiment used a discrete-trial procedure similar to Nevin's to train a simultaneous line-tilt discrimination in pigeons. Generalization tests involved the simultaneous presentation of pairs of values along the line-tilt dimension according to the method of paired comparisons. In addition, the birds were exposed to a test procedure which allowed free responding to the paired stimuli. Generalization gradients were derived by summing the response frequencies to each stimulus (cf. Honig, 1962). Thus, it was possible to make a direct comparison of choice and frequency measures of stimulus control.

\section{SUBJECTS}

Four experimentally naive male adult homing pigeons were maintained at approximately $80 \%$ of their free-feeding weight throughout the experiment. Water was always available in the individual living cages. APPARATUS

Electromechanical relay circuitry, which controlled the experimental contingencies, was situated remote from the soundproofed and ventilated experimental chamber. On one wall of the chamber were three $2.0-\mathrm{cm}$-diam translucent response keys with $9.8 \mathrm{~cm}$ between their centers and at the same height $(23.5 \mathrm{~cm})$ from the grid floor. From the beginning of the experiment to 1 day before Test 8 , a force of $9 \mathrm{~g}$ was sufficient to operate each key; from then on, the minimum effective force was $12 \mathrm{~g}$. An in-line digital display was mounted behind each key. Three black vertical or horizontal lines on a white surround could be displayed on the center key. Each of the side keys could be transilluminated by a single white line on a dark surround, at any one of seven orientations to the horizontal, from 0 to $90 \mathrm{deg}$ in 15-deg steps. The stimuli provided the only illumination in the dark chamber, except for the magazine light, which signaled 2 -sec access to mixed grain. Responses were recorded on impulse counters.

\section{PROCEDURE}

A $30-\mathrm{min}$ period of adaptation to the experimental chamber on the first day and shaping to peck the key on the second were followed by 5 days of continuously reinforced responding on the center key. During each of these sessions, 100 reinforcements were delivered. Throughout the experiment, the stimulus lines displayed on the center key were vertical for two Ss (P7 and P8) and horizontal for the other two (P9 and P10).

The next eight sessions were devoted to establishing side-key responding. Each trial began with the center key illuminated. One peck on the center key darkened it and simultaneously displayed a 45-deg line on one of the two side keys. The illuminated side key was randomly on the right or left with equal frequency. A single peck at the illuminated side key darkened it and initiated a 2-sec access to mixed grain. For the first three of these eight sessions, a 5 -sec blackout period (TO) followed reinforcement; for the remainder, the TO duration was $10 \mathrm{sec}$.

Discrimination training proceeded from Session 16. Each of 100 trials per session began with the center key illuminated. One peck darkened it and simultaneously displayed a 45-deg line (S+) on one side key and a 30-deg line (for P7 and P8) or a 60-deg line (for $\mathrm{P} 9$ and P10) on the other (S-). S+ and $S-$ were quasirandomly displayed on the left and right keys with equal frequency. A single peck at $\mathrm{S}+$ darkened both keys and produced 2 -sec reinforcement followed by a 10-sec TO. A peck at S- produced the 10-sec TO only. Except for a change in reinforcement probability, this discrimination procedure was in force for the remainder of the experiment. Except for P9, all Ss were trained for 14 sessions in which the reinforcement probability for a correct response was 1.0. Because of the slow acquisition of discrimination over 10 sessions of training with 45 and $60 \mathrm{deg}, P 9$ was trained for an additional seven sessions with an $S-$ of $75 \mathrm{deg}$ and then returned to the original discrimination (S- of $60 \mathrm{deg}$ ) for a further two sessions.

For all birds, discrimination training was continued for the remainder of the experiment with a probability of reinforcement for a correct response on each trial of 0.5 . Generalization tests were interspersed throughout this training. The first test was administered after 11 days of discrimination training with 0.5 reinforcement probability. One further day of training was followed by Test 2. The pattern of training and testing ( 8 days training, test, 1 day training, test) was recycled until nine tests were administered, thus giving a total of 51 days of training with 0.5 reinforcement probability. An exception was that $P 9$ was trained for 14 days before Test 3 . Test 10 was given to all birds after 4 days of training following Test 9 .

Tests 1-9 were identical for all birds. Each test comprised 84 trials in extinction, except Test 8 , which comprised 42 trials. Trials 1 and 43 were preceded by 10 warm-up trials in which the contingency previously in force during discrimination training was in effect. Each test trial began with the center key illuminated. As in training, S's center-key response darkened the key and displayed a pair of test stimuli on the side keys. One response (choice response) to either test stimulus darkened both keys and initiated the 10-sec TO. The test trial was always initiated by S's center-key 


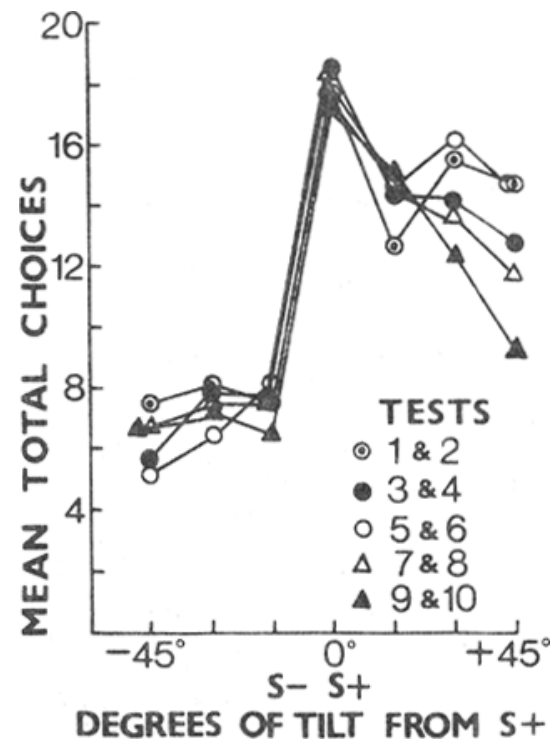

Fig. 1. Stimulus control functions along the line-tilt dimension following simultaneous discrimination. The gradients are averaged over four birds and pairs of tests. Test stimuli were presented according to the method of paired comparisons.

response. If a choice response did not occur within $22.5 \mathrm{sec}$ from the start of the trial, the trial was terminated by $\mathbf{E}$. Few such trials occurred. The test stimuli comprised all possible pairs of values from 0 to $90 \mathrm{deg}$ in 15-deg steps. The test pairs were presented in a random order according to the method of paired comparisons. Each stimulus value occurred equally often on the left and right keys. The order of pairs for Trials 1-42 was reversed for Trials 43-84.

Choice measures of stimulus control were obtained from Tests 1-9. Test 10 afforded both choice and frequency measures. The procedure of Test 10 was the same as for Tests 1-9, except that on each trial the pair of test stimuli remained on the side keys for $5 \mathrm{sec}$, irrespective of S's responding. The initial choice on these trials (as in Tests 1-9) and the frequency of responding to each stimulus were recorded.

\section{RESULTS AND DISCUSSION}

Over the last 50 days of discrimination training with 0.5 reinforcement probability, the accuracy of $S+$ responding was between $95 \%$ and $100 \%$ for P7, P8, and P10. P9's accuracy fluctuated between $82 \%$ and $98 \%$.

The choice measure of stimulus control was derived from the data of Tests $1-10$ as follows: For each test, the total number of choices (or initial choices in Test 10) of each stimulus value when it was paired with every other value was summed over the 84 trials. The maximum possible frequency of choices in one test was 24. Figure 1 shows stimulus control functions combined over the four birds and averaged for the pairs of tests, 1 and 2,3 and 4,5 and 6,7 and 8 , and 9 and 10 . Despite individual variation, these curves accurately reflect the little change that occurred in the individual functions over the 10 tests. Like Honig's (1962) postdiscrimination gradient, the functions are peaked at $\mathrm{S}+$ and are sometimes (for Tests 1 and 2,3 and 4, and 9 and 10 ) inverted around $S-$ The inversions around the stimulus adjacent to S+ $(60$ deg for P7 and P8 and $30 \mathrm{deg}$ for P9 and P10) that occur in Tests 1 and 2 and Tests 5 and 6 might be the result of an interaction between absolute and relational responding; it is difficult to attribute them to stimulus defects, considering that responses to four different stimuli contribute to the data points and that systematic gradients around $45 \mathrm{deg}$ have been obtained following successive discrimination by different groups of Ss in the same apparatus.

The choice measures of stimulus control from Test 10 are plotted in Fig. 2 for the individual Ss. Also shown in Fig. 2 are the frequency functions obtained from Test 10 by summing the frequency of responses made in $5 \mathrm{sec}$ to each stimulus of a pair over the total 2 min during which each stimulus was exposed. The close correspondence between the stimulus control functions derived from the frequency and choice measures demonstrates the comparability of the two measures. The only difference between the functions is that the frequency gradients are sharper than the choice gradients. Perhaps the frequency measure is a slightly more sensitive detector of the stimulus control exerted by $\mathrm{S}+$. The similarity between the two sorts of functions does, however, confirm the reliability of the choice measure, in the context of the discrete-trial paired-comparison procedure, as a measure of stimulus control.

That both types of test function following simultaneous training were peaked at the $S+$ value and did not exhibit the peak shift that characteristically follows successive discrimination (Bloomfield, 1967) is in accord with Honig's (1962) result. But it is not consistent with Winton \& Beale's (1971) reported peak shift following concurrent training. Winton \& Beale (1971) used Findley's (1958) changeover key procedure for scheduling the concurrent discrimination, a procedure which results in the successive presentation of the training stimuli. It may be that, in simultaneous training, differential responding occurs relative to a comparison between the training stimuli and that a necessary condition for peak-shift occurrence is the absence of a comparator.

\section{REFERENCES}

BLOOMFIELD, T M. A peak shift on a line-tilt continuum. Journal of the Experimental Analysis of Behavior, 1967, $10,361-366$

FINDLEY, J, D. Preference and switching under concurrent scheduling. Journal of the Experimental Analysis of Behavior, $1958,1,123-144$.

GUTTMAN, N., \& KALISH, H. I. Discriminability and stimulus generalization. Journal of Experimental Psychology, 1956, 51, 79-88.

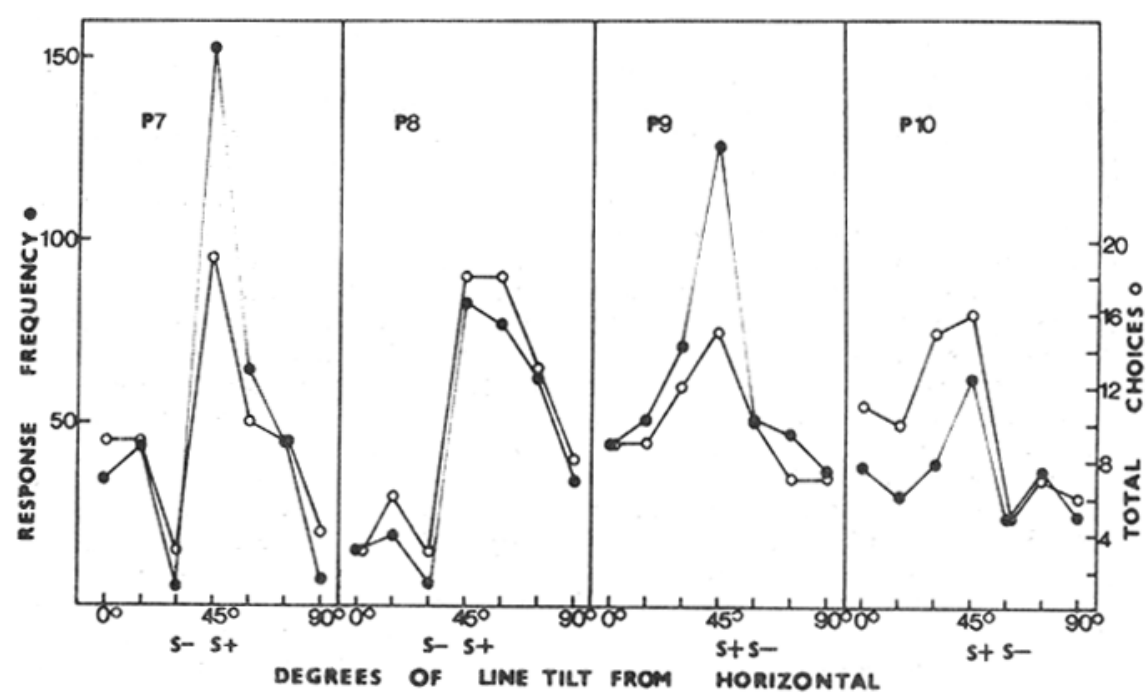

Fig. 2. Stimulus control functions for individual birds. The choice (unfilled circles) and frequency (filled circles) measures were obtained during Test 10. 
HONIG, $W$. K. Prediction of preference transposition, and transposition-reversal from the generalization gradient. Journal of Experimental Psychology, 1962,64, 239-248.

JENKINS, H. M. Measurement of stimulus control during discriminative operant conditioning. Psychological Bulletin. $1965,64,365-376$.

NEVIN, J. A. Effects of reinforcement scbeduling on simultaneous discrimination performance. Journal of the Experimental Analysis of Behavior. $1967,10,251-260$

WINTON, A S. W. \& BEALE, I. L. Peak shift in concurrent schedules. Joumal of the Experimental Analysis of Behavior. $1971,15,73-81$ 